\title{
INTRODUCING A FALL "WELLBEING" WEEK AT UBCO
}

\author{
Ayman Elnaggar and Megan Lochhead \\ The School of Engineering, University of British Columbia, Okanagan Campus \\ ayman.elnaggar@ubc.ca megan.lochhead@ubc.ca
}

\begin{abstract}
Student mental health and well-being are increasingly a focus of post-secondary institutions across Canada. Many academic institutions have opted to offer a fall reading week as a means of reducing student stress and improving their mental health. This paper presents a review of the academic research that has been done to study the impact of a fall reading week on students' mental health and wellbeing. The paper also presents the status of the fall reading break in the top 30 Canadian Universities. Based on the results of this research, the authors have developed a proposal of introducing a fall reading week at the University of British Columbia, Okanagan Campus (UBCO). The proposal has been accepted in concept by the Provost's Office as well as by the Senate's Academic Policy Committee for possible implementation.
\end{abstract}

Keywords: Students' mental health, Fall reading week, Wellbeing week, Students wellbeing, Students Wellness.

\section{INTRODUCTION}

Student mental health and well-being are increasingly a focus of post-secondary institutions and programs across Canada. This is perhaps most evident in demanding programs such as engineering. The typical engineering program requires additional credits above those of a standard arts or sciences degree. Additional credits result in additional hours of class, study, and work on assessments. The stress experienced by engineering students and postsecondary students in general is at an alarming level as is evident in the results of recent academic mental health and wellbeing research [1], [3]-[5]. Additionally, some campuses have have experienced student suicides and attempted suicides and the incidence of these are growing [15]-[18]. Tragically, during the 20102011 academic year, six students at Queen's university committed suicide shaking the academic community in Ontario and across the country [12]. As a result, several large scale surveys and research projects on the mental health and wellbeing of post-secondary students have been initiated. A common recommendation that came out of these surveys and studies was for the implementation of a longer fall break.
UBCO has provided a one day midterm break for students in the fall term; however, many other Canadian institutions are providing their students a full week. The University of Ottawa [29], Trent University [20], and Ryerson University [19] initiated a fall reading week in 2012, followed by Brock University [2] and University of Sherbrook [31] in 2013. The momentum continued with the University of Toronto [32], McMaster University [9], The University of Montreal [27], Laval University [7], Carlton University [6], and the University of Alberta [21] in 2015. Followed by Dalhousie University [7], the University of Windsor [34], the University of Winnipeg [35], and Lethbridge University [25] in 2016. Most recently, York University [38], the University of Calgary [23], the University of Manitoba [26], Western University [37], Regina University [30], and the University of Ontario-Institute of Technology [28] implemented a fall reading week in the 2018-2019 academic year. Other universities have opted for a shorter fall break. As an example, the University of Victoria [33], Waterloo University [36], and Queen's University [13] have implemented a two-day fall break, while Guelph University [24] and Memorial University of Newfoundland [11], similar to UBCO, have opted for a one day break. By the start of 2019, more than 50 universities and colleges nation-wide have implemented different models of longer fall breaks. Out of the top 30 Canadian Universities, UBC (Vancouver Campus), McGill University, Concordia University, and SFU are the only four institutions who have not instated any fall break [22]. Appendix 1 summarizes the current status of the top 30 Canadian Universities.

Many universities have explored different models in adopting the weeklong fall break into their calendar. Most universities have opted to have the break overlap with either the Thanksgiving or Remembrance Day holidays. A few universities, however, have chosen different dates. For example, the University of Ottawa chose the middle of the term in late October [29]. Brock University, on the other hand, specifically chose the week during which the most suicides have historically occurred [2]. Regardless of the date of the break, the main challenge that all universities have been facing was how to compensate for lost instructional days in an already limited semester. 
While most of the universities in Ontario have chosen to shrink the fall term to 12 weeks, UBCO policy requires at least 60 instruction days. The multiple long weekends in the fall, as well as the minimum number of contact hours required by some accreditation associations make this model not viable at UBCO. The University of Calgary chose to start the fall semester earlier, during the last week of August [23]. In addition to being logistically difficult, if not impossible, to implement this model at UBCO, a major downfall of starting in August is the availability of housing on-campus. Many students are forced to rent off-campus housing and they would then have to pay rent for the additional month of August.

This research for the inclusion of a weeklong break in Term 1 has arisen out of concern for our students' mental health and well-being. While originally desired for year one engineering students who are dealing with many stressful deliverables and deadlines during their first transition experience to post-secondary studies, it became apparent that all students on campus would benefit from this time off.

\section{RATIONALE}

We believe a week long term one break will have a positive impact on the mental health and wellbeing of our students. In 2013, the American College Health Association ran a massive survey across 30 post-secondary institutions in Canada [1]. A total of $89.3 \%$ of respondents felt overwhelmed, $86.9 \%$ felt exhausted, and $56.5 \%$ felt immense anxiety. A majority of students $(56.6 \%)$ reported academic issues as traumatic or very difficult to handle. The Canadian Association of College and University Student Services ran a larger follow-up survey in 2016 that captured similar responses from 43,000 students in 41 Canadian institutions [4]. The surveys data supported previous trends indicating that the mental health of our students is in crisis. Anxiety and depression were reported to be the most common mental illnesses experienced by students. Moreover, $13 \%$ of survey respondents had considered suicide within the last 12 months: a $3.5 \%$ increase compared to the previous survey in 2013. Although alarming, these data are not surprising. In 2016, The Canadian Mental Health Association stated suicide as the second leading cause of death among 15-24-year-olds [5].

The serious state of our student's mental health is evident in the rising occurrence of campus tragedies. During the 2016-1027 academic year the University of Guelph lost four students to suicide [15]. Three of the four were first-year students. Two of the suicide cases were reported in November, while the other two cases were reported in early January. Likewise in 2016-2017, the University of Waterloo had two students, one being a first year, commit suicide [16]. Then again in March 2018, another Waterloo student committed suicide [17]. While there is no proven correlation between these tragic incidents and the fall reading break, it is worth noting that the University of Guelph and the University of Waterloo are both among the few universities that practice a reduced fall break at one and two days, respectively. In response to these tragedies, 15,000 Waterloo students signed a petition, asking the university to foster student mental health on campus [18].

Even though there is currently no empirical evidence linking study breaks to improved mental health for students, a number of universities have been studying the impacts of their fall breaks and have presented qualitative evidence from their students to support the inclusion of the fall break. A Doctoral student at Brock University has conducted the most academic work on the subject [3]. She reported that the overwhelming perception amongst students is that a fall break was helpful and reduced their stress, this was especially true for first year students. Researchers at McMaster University have conducted a multi-institutional project to measure the impact of fall reading week on students' stress [10]. Their findings too suggested that students' wellbeing has improved. Another interesting finding was that students whose universities have implemented the fall break around Thanksgiving had wished the fall break was pushed back to Remembrance Day.

In May 2017, the National Conference on Campus Mental Health attracted many mental health higher education administrators and experts from many universities all over the country [12]. Statistics presented at the conference showed that while the University of Montreal has witnessed an increase of $8.5 \%$ in the number of students suffering mental health problems and those seeking help and counselling during the period of 20132016, McGill University has witnessed a dramatic increase of $110 \%$ during the same period. As shown in Appendix 1, the University of Montreal has been practicing the fall reading week break for more than three years, while McGill University has not yet implemented a fall break.

A fall break could improve students' mental health and wellbeing by allowing students the time to focus on themselves and their needs. By doing so, students return to class feeling relaxed and equipped. This break is particularly valuable for first-year students who are adapting to the university experience and suffer the most from homesickness. This mental break will allow students a chance to catch up and to reflect on their learning and performance after their midterm exams, and to better prepare for their final exams.

In fact, the fall break will also allow faculty to catch up, focus on their research and grant proposals, reflect on their teaching and their students' performance and use this feedback to better plan and construct the remaining few weeks of classes and the final exam. This will also allow community to spend more time with their families over the holidays. 


\section{THE PROPOSAL MODEL}

Our proposed model is very similar, in most of the parts, to the models that have been successfully practiced and implemented by many universities such as University of Toronto [32] and Dalhousie University [7]. Our main contribution; however, is utilizing the flexibility of the existing policy that allows Term 1 start date to optionally be prior to Labour Day compared to the typical practice of being on Tuesday following Labour Day. Additionally, the proposed model complies with other constraints of the policy such as minimum instruction days, minimum contact hours, term end dates, as well as exam periods.

We propose to add three additional break days surrounding the Remembrance Day holiday and the existing mid-term break day. This results in a total of five days or a weeklong break to be added to our academic calendar.

The implementation includes:

- Start Term 1 on the Tuesday following Labour Day (being the typical practice), unless this creates an issue in achieving the minimum number of teaching/instruction days. In this case, start Term 1 classes on September $2^{\text {nd }}$, before Labour Day;

- Students move in and settle down on all morning and afternoon of September $1^{\text {st }}$,

- A brief orientation for first year students on the evening of September 1st to introduce the students to the main facilities and resources on campus; (Dalhousie runs the induction orientation on move-in day)

- A longer one, two, or three-day orientation activities and programs such as Imagine and Create on the Labour Day weekend.

- Push back Term 1 classes and exam period further into December but no later than December 22 $2^{\text {nd. }}$

- Maintain at least two reading days between end of classes and start of exam period;

- Change the Start date of Term 2 to the second Monday following January $1^{\text {st }}$, unless this creates an issue in achieving the minimum number of teaching days or teaching weeks, in which case it will begin the week prior.

- Push back Term 2 classes and exam period further into April but no later than April $30^{\text {th }}$.

- The proposed model also results in an extended 14-18 days Christmas break. Students will be enjoying longer Christmas holidays with their families that further enhances their mental health and wellbeing.

\subsection{Policy Changes}

In this section, we present the impact of our proposed model on the existing policy, if there is any.

\section{Term Start Dates}

1) Term 1 may begin prior to Labour Day, although not earlier than September 1. The Tuesday following Labour Day is the typical Term 1 start date.

2) Term 2 shall begin the Monday following January 1 unless this creates an issue in achieving the minimum number of teaching days or teaching weeks set out in sections (1) and (2), in which case it will begin the week prior.

Changes required: Term 2 shall begin the second Monday following January 1 unless this creates an issue in achieving the minimum number of teaching days or teaching weeks set out in sections (1) and (2), in which case it will begin the week prior.

\section{Examination Periods}

3) There shall be at least two (2) calendar days, including weekends and university-recognized holidays, between the last day of classes in a Winter Session term and the beginning of formal examinations.

4) Up to 14 examinable days may be scheduled including Saturdays but not Sundays for each Formal Examination Period in the Winter Session.

5) Winter Term 1 formal examinations conclude not later than December 22; Winter Term 2 formal examinations conclude no later than April 30.

Changes required: No changes.

\section{Term 1 Mid-term Break}

6) A one-day mid-term break shall be scheduled during Term 1, directly preceding or directly following the November 11 statutory holiday or UBC holiday in lieu.

Changes required: A four-day mid-term break shall be scheduled during Term 1, directly preceding or directly following, or surrounding the November 11 statutory holiday or UBC holiday in lieu.

\section{Term 2 Mid-term Break}

7) A four-day mid-term break shall be scheduled during Term 2

Changes required: No changes.

\subsection{Challenges}

We are aware of some challenges that the proposed model may impose on the UBC community. Some of these challenges, even though they do not necessarily require changes to the existing policy, may change typical practices that have been implementing for many years. We also believe that there are challenges that we are not aware of that may rise during further consultations with different stakeholders on campus.

\subsection{Recommendations}

The main goal of the fall break is to allow students time to catch up and to reflect on their learning and 
performance in order to enhance their mental health and wellbeing. We recommend therefore, to use a meaningful name that reflects this goal. "Wellbeing Week". "Reading week" or "Study week" maybe misleading to students as well as to faculty. Some research and survey results have shown that many faculty from other universities who have been implementing the fall break, have overloaded the students with academic tasks and deliverables to work on during that week resulting in even more stress on the students than a normal class week. The name will always remind the UBCO community of the fall break goals. This will also help promote a new academic culture that works best for the students' mental health and wellbeing. Using a name such as "wellbeing week" will allow UBCO to build on the existing research and lead the way among universities for an innovative "student-centered" educational practice.

This initiative is one opportunity for our campus to improve conditions for all students, including those suffering with mental health related issues. However, there is still work to be done. Institutions need to be open to development and adaptations as our student populations evolve. Instead of digging our heels in and continuing forward as we have always done, we need to keep our eyes open for future opportunities to improve student life and academic experiences. It is only with this foresight that we can hope to avoid unnecessary tragedies in the future.

\section{References}

[1] American College Health Association, Survey Results, Available as of March 3, 2019, from https://www.acha.org/documents/ncha/ACHANCHAII_CANADIAN_ReferenceGroup_ExecutiveSummar y_Spring2013.pdf

[2] Brock University, Fall Reading Week, Available as of March 3, 2019, from https://brocku.ca/brock-news/2012/12/fall-readingweek-coming-in-2013/

[3] Broke University, Research on impact of fall reading week on students' mental health and wellbeing, Available as of March 3, 2019, from https://brocku.ca/webfm_send/33279

[4] Canadian Association of College and University Student Services, Survey Results, Available as of March 3, 2019, from https://www.cacuss.ca/resources/publications-andwebinars.html

[5] Canadian Mental Health Association, Survey Results, Available as of March 3, 2019, from https://cmha.ca/about-cmha/fast-facts-about-mental$\underline{\text { illness }}$
[6] Carlton University, Fall Reading Week, Available as of March 3, 2019, from https://cusjc.ca/ypolitics/fall-breaks-here-to-stay-onmore-ontario-university-campuses/

[7] Dalhousie University, Fall Reading Week, Available as of March 3, 2019, from https://www.dal.ca/news/2015/11/20/dal-approvesfall-study-break--revamps-academic-termschedule.html

[8] Laval University, Fall Reading Week, Available as of March 3, 2019, from https://www4.fsa.ulaval.ca/en/international/incomingexchange-students/academic-calendar/

[9] McMaster University Fall Reading Week, Available as of March 3, 2019, from https://dailynews.mcmaster.ca/articles/momasterapproves-full-week-fallbreak/\#sthash.khKumSzO.dpuf

[10] McMaster University, Research on impact of fall reading week on students' mental health and wellness, https://celt.uwindsor.ca/index.php/CELT/article/view/ $\underline{4757}$

[11] Memorial University of Newfoundland, Fall Reading Week,

Available as of March 3, 2019, from https://www.mun.ca/regoff/calendar/sectionNo=GENI NFO-0086

[12] National Conference on Campus Mental Health for Higher Education Administrators, Available as of March 3, 2019, from https://montrealgazette.com/news/local-news/mental-health-oncampus

[13] Queen's University, Fall Reading Week, Available as of March 3, 2019, from https://www.queensu.ca/gazette/stories/senateapproves-fall-term-break

[14] Queen's University, Student Deaths on Campus, Available as of March 3, 2019, from https://www.theglobeandmail.com/news/national/stud ent-deaths-leave-queens-struggling-foranswers/article575727/

[15] Recent suicide cases, Guelph University, Available as of March 3, 2019, from https://www.universityaffairs.ca/features/featurearticle/a-death-on-campus/

[16] Recent suicide cases, Waterloo University, Available as of March 3, 2019, from https://www.thestar.com/news/gta/2017/08/12/howmany-ontario-post-secondary-students-die-by-suicideeach-year-no-one-knows-for-sure.html 
[17] Recent suicide cases, Waterloo University, Available as of March 3, 2019, from https://www.cbc.ca/news/canada/kitchenerwaterloo/university-waterloo-president-letter-student$\underline{\text { suicide- } 1.4038503}$

[18] Recent suicide cases, Waterloo University, Available as of March 3, 2019, from https://www.therecord.com/news-story/8298413-uwstudent-dies-by-suicide-at-student-residence/

[19] Ryerson University, Fall Reading Week, Available as of March 3, 2019, from https://www.macleans.ca/education/uniandcollege/fall -reading-weeks-on-the-rise/

[20] Trent University, Academic Calendar, Available as of March 3, 2019, from http://digitalcollections.trentu.ca/objects/tula2713\#page/1/mode/2up

[21] University of Alberta, Fall Reading Week, Available as of March 3, 2019, from https://www.folio.ca/ualberta-introduces-fall-readingweek/

[22] University of British Columbia, Fall Reading Week, Available as of March 3, 2019, from https://www.ubyssey.ca/news/2018-and-still-noreading-break/

[23] University of Calgary, Fall Reading Week, Available as of March 3, 2019, from https://www.ucalgary.ca/pubs/calendar/current/acade mic-schedule.html\#fall2017

[24] University of Guelph, Fall Reading Week, Available as of March 3, 2019, from https://www.uoguelph.ca/registrar/calendars/undergrad uate/2018-2019/c03/c03-fallsem.shtml

[25] University of Lethbridge, Fall Reading Week, Available as of March 3, 2019, from https://globalnews.ca/news/2403237/students-atuniversity-of-lethbridge-will-get-fall-break/

[26] University of Manitoba, Fall Reading Week, Available as of March 3, 2019, from http://news.umanitoba.ca/2018-2019-academicschedule-to-include-weeklong-fall-break-in$\underline{\text { november/ }}$

[27] University of Montreal, Fall Reading Week, Available as of March 3, 2019, from https://registraire.umontreal.ca/datesimportantes/calendriers-universitaires/
[28] University of Ontario, Fall Reading Week, Available as of March 3, 2019, from http://calendar.uoit.ca/content.php?catoid=20\&navoid $=816$

[29] University of Ottawa, Academic Calendar, Available as of March 3, 2019, from https://www.uottawa.ca/important-academic-datesand-deadlines/important-dates-and-deadlines-2012$\underline{2013}$

[30] University of Regina, Fall Reading Week, Available as of March 3, 2019, from https://www.cbc.ca/news/canada/saskatchewan/u -of-r-new-fall-break-1.4889548

[31] University of Sherbrooke, Academic Calendar, Available as of March 3, 2019, from https://www.usherbrooke.ca/registraire/fileadmin/sites /registraire/documents/Droit_Calendriers/droit_politiq ues sante 2013-2014.pdf

[32] University of Toronto, Fall Reading Week, Available as of March 3, 2019, from https://www.utm.utoronto.ca/fall-reading-week/fallreading-week-proposal http://www.artsci.utoronto.ca/current/course/timetable $\underline{/ 1819 \text { fw/2018_fall_dates }}$

[33] University of Victoria, Fall Reading Week, Available as of March 3, 2019, from https://web.uvic.ca/calendar201809/general/dates.html

[34] University of Windsor, Fall Reading Week, Available as of March 3, 2019, from http://www.uwindsor.ca/registrar/501/importantacademic-dates-semester

[35] University of Winnipeg, Fall Reading Week, Available as of March 3, 2019, from http://news-centre.uwinnipeg.ca/all-posts/uwinnipegto-introduce-fall-reading-week/

[36] Waterloo University, Fall Reading Week, Available as of March 3, 2019, from https://uwaterloo.ca/associate-vice-presidentacademic/fall-break-project

[37] Western University, Fall Reading Week, Available as of March 3, 2019, from http://www.westerncalendar.uwo.ca/SessionalDa $\underline{\text { tes.cfm }}$

[38] York University, Fall Reading Week, Available as of March 3, 2019, from http://vpstudents.yorku.ca/vpsnews/2017/11/28/fallreading-week-returns-to-york-university/ 
APPENDIX 1: FALL BREAKS AT THE TOP 30 CANADIAN UNIVERSITIES

\begin{tabular}{|c|c|c|c|}
\hline University & $\begin{array}{c}\text { Starting Year of } \\
\text { Fall Break }\end{array}$ & $\begin{array}{l}\text { Length of } \\
\text { Fall Break }\end{array}$ & Dates of Fall Break \\
\hline Ryerson University & 2012 & Weeklong & Thanksgiving \\
\hline University of Ottawa & 2012 & Weeklong & Last week of October \\
\hline Trent University & 2012 & Weeklong & Last week of October \\
\hline Brock University & 2013 & Weeklong & Thanksgiving \\
\hline University of Sherbrooke & 2013 & Weeklong & Week 3 of October (middle of the semester) \\
\hline University of Toronto & 2015 & Weeklong & Thanksgiving \\
\hline McMaster University & 2015 & Weeklong & Thanksgiving \\
\hline University of Montreal & 2015 & Weeklong & Week 3 of October (middle of the semester) \\
\hline Laval University & 2015 & Weeklong & Last week of October \\
\hline Carlton University & 2015 & Weeklong & Last week of October \\
\hline University of Alberta & 2015 & Weeklong & Remembrance Day \\
\hline University of Windsor & 2016 & Weeklong & Thanksgiving \\
\hline University of Winnipeg & 2016 & Weeklong & Thanksgiving \\
\hline Dalhousie University & 2016 & Weeklong & Remembrance Day \\
\hline University of Lethbridge & 2016 & Weeklong & Remembrance Day \\
\hline York University & 2018 & Weeklong & Thanksgiving \\
\hline University of Calgary & 2018 & Weeklong & Thanksgiving \\
\hline Western University & 2018 & Weeklong & Thanksgiving \\
\hline University of Manitoba & 2018 & Weeklong & Thanksgiving \\
\hline $\begin{array}{l}\text { University of Ontario - } \\
\text { Institute of Technology }\end{array}$ & 2018 & Weeklong & Thanksgiving \\
\hline University of Regina & 2018 & Weeklong & Remembrance Day \\
\hline University of Waterloo & 2016 & Two Days & Thanksgiving \\
\hline Queen's University & 2018 & Two Days & Thu \& Fri on week 7 of the Semester \\
\hline University of Victoria & $\mathrm{N} / \mathrm{A}$ & Two Days & Remembrance Day \\
\hline University of Guelph & N/A & One Day & Thanksgiving \\
\hline $\begin{array}{c}\text { Memorial University of } \\
\text { Newfoundland }\end{array}$ & $\mathrm{N} / \mathrm{A}$ & One Day & Thanksgiving \\
\hline UBC (Okanagan Campus) & 2005 & One Day & Remembrance Day \\
\hline McGill University & - & None & \\
\hline Concordia University & - & None & \\
\hline Simon Fraser University & - & None & \\
\hline $\begin{array}{c}\text { UBC (Vancouver } \\
\text { Campus) }\end{array}$ & - & None & \\
\hline
\end{tabular}




\section{APPENDIX 2: A SAMPLE OF THE 7-YEAR CALENDAR PLAN}

\section{$2020 / 2021$}

\begin{tabular}{|c|c|c|c|c|c|c|c|c|c|c|c|c|c|c|c|c|c|c|c|c|c|c|c|c|c|c|c|}
\hline \multicolumn{7}{|c|}{ September 2020} & \multicolumn{7}{|c|}{ October 2020} & \multicolumn{7}{|c|}{ November 2020} & \multicolumn{7}{|c|}{ December 2020} \\
\hline \multirow[t]{2}{*}{ Su } & Mo & Tu & We & Th & Fr & Sa & Su & Mo & Tu & We & Th & Fr & Sa & Su & Mo & Tu V & We $T$ & Th F & Fr $s$ & Sa & Su & Mo & Tu & We & Th & Fr & Sa \\
\hline & & 1 & 2 & 3 & 4 & 5 & & & & & 1 & 2 & 3 & 1 & 2 & 3 & 4 & 5 & 6 & 7 & & & 1 & 2 & 3 & 4 & 5 \\
\hline 6 & $\underline{7}$ & 8 & 9 & 10 & 11 & 12 & 4 & 5 & 6 & 7 & 8 & 9 & 10 & 8 & 9 & 10[ & $\underline{\underline{11}} 1$ & 12 & 131 & 14 & 6 & 7 & 8 & 9 & 10 & 11 & 12 \\
\hline 13 & 14 & 15 & 16 & 17 & 18 & 19 & 11 & $\underline{12}$ & 13 & 14 & 15 & 16 & 17 & 15 & 16 & 17 & $18 \quad 1$ & 19 & 20 & 21 & 13 & 14 & 15 & 16 & 17 & 18 & 19 \\
\hline 20 & 21 & 22 & 23 & 24 & 25 & 26 & 18 & 19 & 20 & 21 & 22 & 23 & 24 & 22 & 23 & 242 & \begin{tabular}{l|l}
25 & 2 \\
\end{tabular} & $26 \quad 2$ & $27 \mid 2$ & 28 & 20 & 21 & 22 & 23 & 24 & $\underline{\underline{25}}$ & 26 \\
\hline 27 & 28 & 29 & 30 & & & & 25 & 26 & 27 & 28 & 29 & 30 & 31 & 29 & 30 & & & & & & 27 & 28 & 29 & 30 & 31 & & \\
\hline \multicolumn{7}{|c|}{$\begin{array}{l}\text { Term-1 Starts on September } \mathbf{2} \\
\text { Labour Day is on September } 7\end{array}$} & \multicolumn{7}{|c|}{ Thanksgiving is on October $\underline{\mathbf{1 2}}$} & \multicolumn{7}{|c|}{ Fall Reading Week } & \multicolumn{7}{|c|}{$\begin{array}{l}\text { - } 61 \text { Instruction days } \\
\text { - } 14 \text { exam days } \\
\text { - } 14 \text { Days Christmas break }\end{array}$} \\
\hline \multicolumn{7}{|c|}{ January 2021} & \multicolumn{7}{|c|}{ February 2021} & \multicolumn{7}{|c|}{ March 2021} & \multicolumn{7}{|c|}{ April 2021} \\
\hline \multirow[t]{2}{*}{ Su } & Mo & Tu & We & Th & Fr & Sa & Su & Mo & Tu & We & Th & Fr & Sa & Su & Mo & Tu & We 1 & Th 1 & Fr & Sa & Su & Mo & Tu & We & Th & Fr & Sa \\
\hline & & & & & $\underline{1}$ & 2 & & 1 & 2 & 3 & 4 & 5 & 6 & & 1 & 2 & 3 & 4 & 5 & 6 & & & & & 1 & $\underline{2}$ & 3 \\
\hline 3 & 4 & 5 & 6 & 7 & 8 & 9 & 7 & 8 & 9 & 10 & 11 & 12 & 13 & 7 & 8 & 9 & 10 & 11 & 12 & 13 & $\underline{4}$ & $\underline{5}$ & 6 & 7 & 8 & 9 & 10 \\
\hline 10 & 11 & 12 & 13 & 14 & 15 & 16 & 14 & $\underline{15}$ & 16 & 17 & 18 & 19 & 20 & 14 & 15 & 16 & 17 & 18 & 19 & 20 & 11 & 12 & 13 & 14 & 15 & 16 & 17 \\
\hline 17 & 18 & 19 & 20 & 21 & 22 & 23 & 21 & 22 & 23 & 24 & 25 & 26 & 27 & 21 & 22 & 23 & 242 & 25 & 26 & 27 & 18 & 19 & 20 & 21 & 22 & 23 & 24 \\
\hline 24 & 25 & 26 & 27 & 28 & 29 & 30 & 28 & & & & & & & 28 & 29 & 30 & 31 & & & & 25 & 26 & 27 & 28 & 29 & 30 & \\
\hline 31 & & & & & & & & & & & & & & & & & & & & & & & & & & & \\
\hline \multicolumn{7}{|c|}{ Term-2 Starts on January 6} & \multicolumn{7}{|c|}{$\begin{array}{l}\text { Spring Reading Week } \\
\text { Family Day is on February } \underline{\mathbf{1 5}}\end{array}$} & & & & & & & & \multicolumn{7}{|c|}{$\begin{array}{l}\text { - } 61 \text { Instruction days } \\
\text { - } 14 \text { exam days } \\
\text { - Good Friday is on Apr } \underline{\mathbf{2}} \\
\text { - } \text { Easter Monday is on Apr } \underline{\mathbf{5}}\end{array}$} \\
\hline
\end{tabular}

